\section{Incrementando o Programa de Controle da} Esquistossomose

Scaling up the Brazilian Schistosomiasis Control Program

Otávio Sarmento Pieri 1

Tereza Cristina Favre 1 ${ }_{1}$ Instituto Oswaldo Cruz, Fundação Oswaldo Cruz,
Rio de Janeiro, Brasil.

\section{Correspondência}

O. S. Pieri

Laboratório de Eco-epidemiologia e Controle da Esquistossomose e Geohelmintoses,

Departamento de Biologia, Instituto Oswaldo Cruz, Fundação Oswaldo Cruz.

Av. Brasil 4365, Rio de Janeiro, RJ 21045-900, Brasil. opieri@ioc.fiocruz.br

A oportuna avaliação que de Farias et al. 1 fazem sobre o Sistema de Informação do Programa de Controle da Esquistossomose (SISPCE) expõe várias questões pertinentes. Pelo menos três delas exigem atenção urgente: (i) a confiabilidade das estimativas de prevalência para Schistosoma mansoni baseadas nas informações disponíveis sobre as atividades do programa; (ii) o aprimoramento do fluxo de informação entre as instâncias locais, estaduais e nacionais do programa; (iii) as perspectivas de atendimento à meta mínima da Resolução 54.19 da Assembléia Mundial de Saúde (AMS) 2. As considerações abaixo visam a contribuir para o equacionamento dessas questões em curto prazo, tendo em vista as dificuldades atualmente enfrentadas pelos formuladores, gestores e executores do programa.

\section{Confiabilidade das estimativas sobre esquistossomose}

Tanto os relatórios das Secretarias Estaduais de Saúde quanto os dados consolidados pelo SISPCE são, tecnicamente, resumos de atividades de coproscopia e tratamento realizadas ano a ano. Por isso, não podem ser interpretados como ciclos sucessivos de diagnóstico populacional e tratamento ou séries históricas. A credibilidade dessas informações depende de um trabalho detalhado de depuração dos dados para evitar vieses de precisão e validade. Por exemplo, um estudo recente avaliando os dados do Programa de Controle da Esquistossomose do Sistema Único da Saúde (PCE-SUS) sobre a Zona da Mata Pernambu- cana identificou apenas seis municípios, de um total de 43, com estimativas minimamente fidedignas; isso impedia qualquer avaliação confiável sobre a atual situação da esquistossomose naquela importante área endêmica 3 .

\section{Fluxo de informação nas ações de vigilância e controle}

As ações de vigilância e controle da esquistossomose dependem da disponibilidade, em curto prazo, de dados fidedignos sobre a prevalência e a intensidade da infecção. Sistemas de informação confiáveis são também necessários para atender à crescente demanda global de dados sobre as ações de controle das verminoses nos países endêmicos. As seguintes medidas podem ser tomadas para garantir um fluxo minimamente fidedigno de informação entre os níveis local, regional e nacional:

- No nível local, as Secretarias Municipais de Saúde devem realizar a transferência anual dos dados coletados para mídia não perecível. Assim, as informações pessoais (nome, idade, sexo, moradia), parasitológicas (número de ovos por lâmina) e status do tratamento (adesão, contra-indicação, tipo e quantidade do medicamento administrado) estarão disponíveis para monitoramento e avaliação em médio e longo prazo;

- No nível regional, as Secretarias Estaduais de Saúde devem consolidar as informações sobre as atividades de coproscopia e tratamento nos municípios de forma criteriosa, identificando e corrigindo as fontes de dados insuficientes ou inconsistentes para garantir estimativas confiáveis sobre a prevalência e a intensidade da infecção;

- No nível nacional, a Secretaria de Vigilância em Saúde do Ministério da Saúde (SVS-MS) deve proceder à análise dos indicadores e à divulgação dos resultados com base nos dados que atendam a critérios mínimos de fidedignidade.

\section{Atendimento à meta mínima da Resolução 54.19}

A SVS-MS recomenda aos municípios endêmicos a realização de inquéritos coproscópicos bienais de toda a população, seguidos de tratamento quimioterápico dos portadores da infecção, além de medidas profiláticas como educação em saúde ${ }^{4}$. Se essas recomendações forem satisfatoriamente seguidas pelas equipes de atenção básica à saúde, a meta mínima da AMS de dar cobertura a pelo menos $75 \%$ das crianças em idade escolar nas áreas endêmicas até o ano 2010 será facilmente suplantada. Infelizmente, os prognósticos não são favoráveis. Por exemplo, um estudo recente na Zona da Mata Pernambucana 5 mostrou que, até 2004 , apenas $8,4 \%$ da população de 1,2 milhão de habitantes haviam sido atendidos e que pelo menos 154 mil crianças em idade escolar precisariam ser examinadas (e tratadas se positivas) para atender 
à meta mínima da Resolução 54.19. É importante que a SVS-MS identifique os fatores responsáveis por esse baixo desempenho e avalie se a cobertura pode ser aumentada para um nível satisfatório dentro das capacidades dos municípios.

Uma estratégia operacional capaz de adequar as recentes recomendações da Organização Mundial da Saúde (OMS) 2 à situação brasileira seria incluir ações de diagnóstico, tratamento e educação em saúde dirigidas às crianças em idade escolar. O pressuposto é que uma ampla cobertura das escolas de ensino fundamental, complementada pela busca ativa das crianças em idade escolar que moram nas redondezas, mas não freqüentam a escola, muito provavelmente bastaria para atingir a meta mínima para $2010{ }^{5}$. Esta estratégia contempla o desenvolvimento de ações intersetoriais focalizadas sobre os grupos de risco, que é uma característica do próprio processo de trabalho das equipes de atenção básica ${ }^{6}$. Uma forma de implementá-la é através do recém instituído Programa de Desenvolvimento da Educação (PDE), que prevê a integração do Programa Saúde da Família (PSF) nas escolas e que conta com o apoio expresso do atual Ministro da Saúde.

\section{Comentários finais}

O controle da esquistossomose nas áreas endêmicas do Brasil depende de conhecimentos técnicos e científicos obtidos por pesquisas realizadas tanto local quanto globalmente. Os órgãos de saúde encarregados de planejar e implementar as estratégias de vigilância e controle em nosso país vêm, há décadas, incorporando os novos conhecimentos e adequandoos às peculiaridades de cada área. Porém, nem sempre a consolidação desses esforços tem sido feita com a eficácia desejada. Tanto a Resolução 54.19 da AMS quanto as Metas para Desenvolvimento do Milênio oferecem uma oportunidade sem precedentes para que todas as instâncias comprometidas com o controle da esquistossomose e outras verminoses unam seus esforços desde já. É claro que, mesmo concentrando os esforços iniciais nos grupos mais vulneráveis e estabelecendo as metas de curto e médio prazo, o programa não deve perder de vista os princípios gerais da política nacional de atenção básica 6 .

1. Farias LMM, Resendes APC, Sabroza PC, SouzaSantos R. Análise preliminar do Sistema de Informação do Programa de Controle da Esquistossomose no período de 1999 a 2003. Cad Saúde Pública 2007; 23:235-9.

2. World Health Organization. Prevention and control of schistosomiasis and the soil-transmitted helminthiasis. Geneva: World Health Organization; 2002. (Report of a WHO Expert Committee).

3. Favre TC, Ximenes RAA, Galvão AF, Pereira APB, Wanderley TN, Barbosa CS, et al. Reliability of current estimates of schistosomiasis prevalence in the Rainforest Zone of the state of Pernambuco, Northeastern Brazil. Mem Inst Oswaldo Cruz 2006; 101 Suppl 1:73-8.

4. Secretaria de Vigilância em Saúde, Ministério da Saúde. Guia de vigilância epidemiológica. Brasília: Ministério da Saúde; 2005.

5. Favre TC, Ximenes RAA, Galvão AF, Pereira APB, Wanderley TN, Barbosa CS, et al. Attaining the minimum target of resolution WHA 54.19 for schistosomiasis control in the Rainforest Zone of the state of Pernambuco, Northeastern Brazil. Mem Inst Oswaldo Cruz 2006; 101 Suppl 1: 125-32.

6. Departamento de Atenção Básica, Secretaria de Atenção à Saúde, Ministério da Saúde. Política nacional de atenção básica. Brasília: Ministério da Saúde; 2006.

Submetido em 02/Abr/2007

Versão final reapresentada em 25/Abr/2007

Aprovado em 02/Mai/2007 